\title{
O que é um nome? Mulherismo, Feminismo Negro e além disso*
}

Patricia Hill Collins**

\section{Resumo}

O texto aborda as "diferenças e semelhanças" entre o mulherismo $e$ o feminismo negro no contexto das tradições afro-americanas. $A$ autora considera que esse debate reflete o desafio básico de acolher a diversidade das mulheres negras. Mas, por que o nome dado ao ponto de vista das mulheres negras é tão importante? Por que a busca por uma definição para explicitar o ponto de vista crítico das mulheres afro-americanas esconde muito mais do que revela, pois na busca de uma unidade conceitual deixamos de lado, ou perdemos a questão mais importante: compreender como as vozes das mulheres negras coletivamente constroem, afirmam $e$ mantêm um ponto de vista auto definido e dinâmico.

Palavras-chave: Mulherismo; Feminismo Negro; Ponto de Vista; Racismo e Sexismo.

\footnotetext{
" Recebido em 15 de agosto 2017, aceito em 26 de outubro 2017. Tradução: Angela Figueiredo e Jesse Ferrell. Publicado originalmente em 1996 no Black Scholar Journal. O comitê editorial do cadernos pagu agradece a autorização da autora para tradução deste artigo.

*** Professora de Sociologia da Universidade de Maryland. collinph@umd.edu 
What's in a Name? Womanism, Black Feminism, and Beyond

\begin{abstract}
The text addresses the differences and similarities between womanism and black feminism in the context of African American traditions. The author asserts that this debate reflects the basic challenge of welcoming the diversity of black women. But, why is it that the name given to a black women's standpoint is so important? Because the efforts to label an African American women's critical standpoint obscures much more than it reveals, since in the search for conceptual unity we lose sight of the more important challenge: understanding how the voices of black women collectively construct, affirm, and maintain a self-defined and dynamic standpoint.
\end{abstract}

Keywords: Womanism; Black Feminism; Standpoint; Racism; Sexism. 
As mulheres negras estão a um ponto de tomar uma decisão que em muitos aspectos reflete aquela enfrentada por afroamericanos enquanto coletividade. Baseando-se em parte nos trabalhos inovadores construídos por Toni Cade Bambara, Ntozake Shange, Angela Davis, Toni Morrison, June Jordan, Alice Walker, Audre Lorde e outras mulheres negras que "quebraram o silêncio" na década de 1970, as mulheres afro-americanas nos anos de 1980 e 1990 desenvolveram uma "voz", um ponto de vista autodefinido e coletivo sobre a feminilidade negra (Collins, 1990). Além disso, as mulheres negras usaram esse ponto de vista para responder à representação das mulheres negras nos discursos dominantes (Hooks, 1989). Como resultado dessa luta, as ideias e experiências das mulheres afro-americanas conseguiram uma visibilidade impensável em comparação ao passado.

Mas as mulheres afro-americanas agora estão diante de um momento histórico diferente. As mulheres negras parecem ter uma voz, e com essa voz recém-descoberta vem uma nova série de preocupações. Por exemplo, devemos estar atentas à absorção sedutora das vozes das mulheres negras em salas de aula no ensino superior, onde os textos de mulheres negras ainda são muito mais bem-vindos do que a presença das mulheres negras em si. Enquanto cria uma ilusão de mudança, essa estratégia de inclusão simbólica mascara a continuação das políticas institucionais cotidianas que suprimem e excluem os afroamericanos enquanto coletividade (Carby, 1992; Du Cille, 1994). Do mesmo modo, as relações de mercado capitalistas que transformaram a escrita das mulheres negras em uma mercadoria desejada, ameaçam retirar de suas obras a perspectiva crítica. Inicialmente, entrar no espaço público através de livros, filmes $e$ mídias impressas pareceu revigorante. Mas nos mercados globais, cada vez mais competitivos, em que qualquer coisa que vende será vendida, independentemente das consequências, as "vozes" de mulheres negras agora inundam o mercado. Como outras commodities comercializadas em mercados capitalistas, o 
excedente barateia o valor e a moda de hoje se torna a memória nostálgica de amanhã. ${ }^{1}$

Ironicamente, enquanto uma voz pública que inicialmente provocou perigo, a voz das mulheres negras agora encontra novos desafios. O novo espaço público fornecido pelo sucesso das mulheres negras fez emergir diferenças já existentes entre essas mulheres, estruturadas ao longo dos eixos de sexualidade, classe social, nacionalidade, religião e região. Nesse sentido, se as mulheres afro-americanas podem formar uma "voz" singular sobre a posição da mulher negra, permanece menos como uma questão do que como as vozes das mulheres negras coletivamente constroem, afirmam e mantêm um ponto de vista autodefinido $e$ dinâmico. Dado o contexto político cada vez mais problemático que tem afetado as mulheres negras como um grupo (Massey; Denton, 1993; Squires, 1994), tal solidariedade é essencial. Assim, garantir a unidade do grupo, embora reconhecendo a enorme heterogeneidade que opera dentro dos limites do termo "mulheres negras", compreende um desafio fundamental agora confrontado pelas mulheres afro-americanas.

Os atuais debates sobre se o ponto de vista das mulheres negras deve ser nomeado "mulherismo"2 ou "feminismo Negro" 3 reflete esse desafio básico de acolher a diversidade das mulheres negras. Em seu aclamado volume de ensaios, In Search of Our Mothers' Gardens, Alice Walker (1983) introduziu quatro significados do termo "Mulherismo". De acordo com a primeira definição de Walker, uma "mulherista" era "uma feminista negra

\footnotetext{
1 Aqui a autora se refere exatamente à perda da perspectiva crítica da escrita das mulheres negras em função da comercialização de suas obras, quando essa suposta popularidade precária pode custar o preço da perda da produção do conhecimento crítico. essa nota é da tradutora? Sim, esta nota é das tradutoras.

2 N.T. Optamos por manter o termo entre aspas, toda vez que ele aparece desse modo no texto original. Do mesmo modo que, às vezes, o termo está escrito com letra maiúscula.

3 N.T. Traduzimos o termo womanism por mulherismo, womanist por mulherista e "womanish" "como mulher".
} 
ou feminista da $\operatorname{cor}^{4}$ (1983, xi)". Assim, em algum nível básico, Walker usa os dois termos como sendo praticamente intercambiáveis. Como Walker destaca, muitas mulheres afroamericanas veem pouca diferença entre os dois termos, uma vez que ambos apoiam uma agenda comum de autodefinição $e$ autodeterminação das mulheres negras. Como aponta Barbara Omolade,

Feminismo negro é por vezes referido como Mulherismo porque ambos estão preocupados com as lutas contra o sexismo e o racismo enfrentados pelas mulheres negras, que também são parte dos esforços da comunidade negra para alcançar a igualdade e liberdade (Omolade, 1994:xx).

Mas, apesar da crença nas diferenças expressas por mulheres afro-americanas que se definem como "feministas negras", como "mulheristas", como ambos, ou, em alguns casos, nenhum dos dois, cada vez mais a atenção parece estar voltada para delinear as diferenças, se houver, entre os grupos que se identificam como "mulheristas" ou "feministas negras". O nome dado ao ponto de vista coletivo das mulheres negras parece ter importância, mas por quê?

Neste artigo, exploro algumas das implicações teóricas de usar os termos "mulherismo" e "feminismo negro" para nomear o ponto de vista de mulheres negras. Meu propósito não é classificar as obras de mulheres negras ou afro-americanas em uma ou outra categoria. Em vez disso, pretendo analisar como o esforço para categorizar obscurece os desafios básicos que as mulheres afroamericanas enfrentam enquanto um grupo.

${ }^{4}$ O termo expressa uma coalizão de feministas não brancas na luta contra a supremacia branca nos Estados Unidos e no Canadá, reconhecendo as diferenças nas suas experiências, mas se unindo ao redor de uma experiência compartilhada de racismo sistêmico. 


\section{Mulherismo}

As várias definições do termo "mulherismo" no livro In Search of Our Mothers Gardens de Alice Walker, esclarecem a questão de porque muitas mulheres afro-americanas preferem o termo mulherismo em vez de feminismo negro. Walker oferece dois significados contraditórios de "mulherismo". Por um lado, a autora vê claramente o mulherismo como enraizado na história concreta da opressão racial e de gênero das mulheres negras. Tomando o termo da expressão cultural negra do sul, em que as mães de crianças do sexo feminino dizem "você está agindo como mulher", Walker sugere que a história concreta das mulheres negras promove uma visão de mundo "mulherista", acessível principalmente, e talvez exclusivamente, às mulheres negras. As meninas "como mulheres" agiram de forma escandalosa, corajosa e obstinada, atributos que as livraram das convenções que havia muito tempo limitavam as mulheres brancas. As meninas como mulheres queriam saber mais e em maior profundidade do que era considerado bom para elas. Elas tomavam o controle e eram sérias.

Apesar da sua consideração de que mulheristas são "tradicionalmente universalistas", uma filosofia invocada por sua metáfora do jardim, onde existe espaço para todas as flores florescerem de forma igual e diferente, Walker considera que, simultaneamente, as mulheres negras são, de algum modo, superiores às mulheres brancas por causa dessa tradição popular negra. Definindo mulheristas como o oposto do "frívola, irresponsável, não séria, meninice", Walker constrói as experiências das mulheres negras em oposição às das mulheres brancas. Esse significado de "mulherismo" é um significado que o define como sendo diferente e superior ao feminismo, uma diferença supostamente decorrente das diferentes histórias de mulheres negras e brancas com o racismo americano. Uma frase muito citada de Walker, "mulherismo é feminista como a púrpura 
é lavanda" (1983, xii $)^{5}$, claramente parece destinado a configurar esse tipo de comparação - as mulheres negras são "mulheristas", enquanto as mulheres brancas permanecem meramente "feministas".

Essa forma de entender o termo "mulherismo" faz sentido no contexto das tradições nacionalistas; trata-se da premissa de que negros e brancos não podem atuar como iguais, enquanto habitando o mesmo território ou participando das mesmas instituições sociais (Pinkney, 1976; Van Deburg, 1992). Como a filosofia nacionalista negra postula que as pessoas brancas enquanto um grupo têm interesse em continuar com o sistema de supremacia branca, normalmente vê pouca utilidade na integração dos negros ou da sua assimilação num sistema baseado na subjugação dos negros. A abordagem nacionalista negra também apoia uma superioridade moral negra sobre os brancos por conta do sofrimento negro. $\mathrm{O}$ uso do termo mulherismo proposto por Walker promete às mulheres negras que operam dentro desses pressupostos nacionalistas negros, e que simultaneamente veem a necessidade de abordar questões "feministas" dentro das comunidades afro-americanas, uma reconciliação parcial dessas duas filosofias aparentemente incompatíveis. $\mathrm{O}$ mulherismo oferece uma distância do "inimigo", nesse caso, os brancos em geral $e$ as mulheres brancas em particular, mas ainda levanta a questão de gênero. Devido ao seu endosso ao separatismo racial, esta interpretação do mulherismo oferece um vocabulário para abordar questões de gênero dentro das comunidades afroamericanas, sem pôr em causa o terreno racialmente segregado que caracteriza as instituições sociais americanas.

Esse uso do mulherismo evita uma questão central para muitas feministas brancas, ou seja, encontrar formas de promover a cooperação inter-racial entre as mulheres. As mulheres afroamericanas que abraçam a filosofia nacionalista negra normalmente expressam pouco interesse em trabalhar com

5 Significa que o mulherismo excede ao feminismo da mesma forma que púrpura é uma cor mais profunda e forte que a lavanda. 
mulheres brancas; de fato, as mulheres brancas são definidas como parte do problema. Além disso, a definição de mulherismo de Walker parece fornecer um modo para promover relações mais fortes entre as mulheres e homens negros, uma outra questão muito importante para as mulheres afro-americanas, independentemente da perspectiva política. Mais uma vez, a definição de Walker fornece orientação quando observa que as mulheristas estão "comprometidas com a sobrevivência $e$ integridade das pessoas inteiramente, homens e mulheres" (Walker, 1983:xi). Muitas mulheres negras veem o feminismo como um movimento que, na melhor das hipóteses, é exclusivamente para as mulheres e, na pior das hipóteses, dedicado a atacar ou eliminar os homens. Sherley Williams assume esse ponto de vista quando observa que, em contraste com o feminismo, "pesquisas mulheristas ... supõem que podem falar de forma eficaz e produtiva sobre os homens" (Williams, 1990:70). O Mulherismo aparentemente fornece uma maneira para que as mulheres negras abordem a opressão de gênero, sem atacar os homens negros.

Walker também oferece um sentido visionário ao "mulherismo". Como parte de sua segunda definição, Walker (1983:xi) apresenta uma menina negra colocando uma questão: "Mamãe, por que somos marrom, rosa e amarelo, e os nossos primos são branco, bege e preto?". A raça de cor é justamente como um jardim de flores, em que cada cor das flores é representada, ambos criticam o colorismo ${ }^{6}$ dentro das comunidades afro-americanas e também amplia a noção de humanidade para caber todas as pessoas de cor. Lendo essa passagem como uma metáfora, o mulherismo fornece uma visão em que as mulheres $e$ os homens de diferentes cores coexistem como flores em um jardim e ainda mantêm a distinção e a integridade cultural.

\footnotetext{
${ }^{6}$ O termo colorismo refere-se ao preconceito baseado na cor da pele dentro da comunidade negra.
} 
Esse significado de mulherismo parece enraizado em outra grande tradição política dentro da política afro-americana, ou seja, uma versão pluralista do empoderamento negro (Van Deburg, 1992). O pluralismo vê a sociedade como sendo composta de vários grupos étnicos e de grupos de interesses, os quais competem por bens e serviços. A equidade reside em proporcionar igualdade de oportunidades, direitos e respeito a todos os grupos. Ao reter uma distinção $e$ a integridade cultural negra, o pluralismo oferece uma versão modificada da integração racial que não se baseia na premissa da assimilação individual, mas na integração enquanto grupo. Rejeitando claramente o que elas percebem como sendo a visão limitada do feminismo projetada por mulheres brancas norte-americanas, muitas mulheres teóricas negras têm sido atraídas para essa união do pluralismo $e$ da integração racial nessa interpretação de "mulherismo" proposta por Walker. Por exemplo, o trabalho da feminista negra, a teóloga Katie Geneva Cannon, Ética Mulherista Negra (1988), evoca esse sentido visionário do mulherismo. Como um sistema ético, o mulherismo está sempre sendo construído, não como um sistema fixo $e$ fechado de ideias, mas que evolui continuamente a partir de sua rejeição a todas as formas de opressão e seu compromisso com a justiça social.

A definição de Walker consegue, assim, evocar três perspectivas filosóficas importantes, ainda que contraditórias, que enquadram o pensamento social e político negro, ou seja, o nacionalismo negro, com suas pretensões de superioridade moral e epistemológica das mulheres negras, via o sofrimento da opressão racial e de gênero; o pluralismo pela integridade cultural demonstrada pela metáfora do jardim; e a integração/assimilação, por meio de suas afirmações de que as mulheres negras são "tradicionalmente universalistas" (Van Deburg, 1992). Assim como o nacionalismo negro coexiste em parceria desconfortável com a integração racial, com o pluralismo ocupando o terreno contestado entre os dois, as definições de mulherismo de Walker demonstram contradições comparáveis. Por fundamentar o mulherismo nas experiências concretas de mulheres afro- 
americanas e por também generalizar sobre o potencial de realizar uma visão humanista de comunidade a partir das experiências de mulheres afro-americanas, Walker descreve o potencial de pessoas oprimidas possuírem uma visão e um ponto de vista moral sobre a sociedade que se baseia na sua situação de opressão. Esse ponto de vista também surge como uma base incipiente para uma sociedade apenas mais humanista e justa. Em geral, esses usos do termo "mulherismo" de Walker criam um espaço conceitual que reflete diferenças filosóficas que de fato existem entre as mulheres afro-americanas. $^{7}$

Uma característica particularmente significativa da utilização das mulheres negras do mulherismo diz respeito à parte da definição de Walker que permanece negligenciada. Uma linha mais problemática para aquelas autodefinidas como mulheristas precede a passagem frequentemente citada, "comprometidas com a sobrevivência e integridade das pessoas integralmente, homens e mulheres" (Walker, 1983:xi). Pouco antes que Walker oferece a advertência de que mulheristas, por definição, estão comprometidas com a integridade, ela afirma que uma mulherista é também "(...) uma mulher que ama outras mulheres, sexualmente e/ou não sexualmente" (Walker, 1983:xi). O silêncio relativo das mulheristas sobre essa dimensão fala da ambivalência contínua das mulheres negras em lidar com as relações entre raça, gênero e sexualidade, nesse caso, a sexualidade "tabu" do lesbianismo. Em seu ensaio A Verdade que Nunca é Demais: Lésbicas Negras na Ficção na Década de 1980, a crítica e feminista negra Barbara Smith (1990) considera que as mulheres afroamericanas ainda têm que lidar com a homofobia nas comunidades afro-americanas. Smith aplaude o crescimento das mulheres negras na ficção na década de 1980, mas também observa que, dentro da produção intelectual feminista negra, lésbicas negras continuam a ser ignoradas. Apesar de algumas das mais proeminentes e poderosas pensadoras negras reivindicadas

7 Para um tratamento detalhado de Alice Walker e relação de outras escritoras feministas e a política nacionalista, ver Dubey (1994). 
por ambas, mulheristas e feministas negras, serem lésbicas, esse fato muitas vezes permanece não reconhecido nas obras de escritoras afro-americanas. Da mesma forma que muitas pessoas leem a Bíblia, selecionando cuidadosamente as partes que concordam com sua visão de mundo, rejeitando o resto. Leituras seletivas do mulherismo de Walker produzem resultados comparáveis.

Uma outra característica importante no múltiplo uso das mulheres negras do mulherismo consiste na possibilidade de um deslizamento entre o real e o ideal. Para mim, há uma distinção entre descrever respostas históricas das mulheres negras à opressão racial e de gênero como sendo mulherista, e usar o mulherismo como um termo visionário para delinear uma visão ética ou ideal da humanidade para todas as pessoas. Identificar o potencial libertador no seio das comunidades de mulheres negras que emerge de experiências históricas concretas é bastante diferente de afirmar que as mulheres negras já chegaram a um ponto final e ideal "mulherista". Recusar-se a distinguir cuidadosamente entre esses dois significados colapsa o real histórico e o ideal futuro em uma posição privilegiada para as mulheres afro-americanas no presente. Tomar essa posição é reminiscente da resposta de algumas mulheres negras à agenda feminista branca reconhecidamente limitada da década de 1970. Essas mulheres negras proclamaram que elas já eram "liberadas", enquanto na realidade, isso estava longe de ser a verdade.

\section{Feminismo negro}

As mulheres afro-americanas que usam o termo feminismo negro também acrescentam interpretações divergentes a esse termo. Na definição da teórica feminista negra e ativista Pearl Cleage (1993:28), o feminismo é definido como "a crença de que as mulheres são seres humanos plenos, capazes de participação $e$ liderança em toda a gama de atividades humanas - intelectuais, políticas, sociais, sexuais, espirituais e econômicas". Em seu sentido mais amplo, o feminismo constitui tanto uma ideologia 
como um movimento político global confrontando o sexismo uma relação social na qual os homens, como um grupo, têm autoridade sobre as mulheres enquanto grupo.

Globalmente, a agenda feminista abrange várias áreas importantes. Em primeiro lugar, a situação econômica e as questões relacionadas com a pobreza global das mulheres, tais como oportunidades de educação, desenvolvimento industrial, racismo ambiental, políticas de emprego, prostituição e leis de herança em matéria de propriedade, constituem uma questão fundamental global das mulheres. Direitos políticos para as mulheres, tais como conseguir o voto, direito de participar de reuniões, viajar, obter cargos públicos; os direitos dos presos políticos e violações básicas de direitos humanos contra as mulheres como estupro e tortura, constituem uma segunda área de preocupação. Uma terceira área de preocupação global consiste em problemas conjugais e familiares, como leis de casamento e divórcio, políticas de custódia da criança e trabalho doméstico. Questões de saúde e sobrevivência das mulheres, tais como direitos reprodutivos, gravidez, sexualidade e AIDS constituem outra área de preocupação feminista global. Essa ampla agenda feminista mundial encontra expressões distintas em diferentes regiões do mundo e entre as diversas populações.

Usar o termo "feminismo negro" posiciona as mulheres afroamericanas para examinar como a constelação particular de questões que afetam as mulheres negras nos Estados Unidos faz parte de questões de emancipação das mulheres globalmente (Davis, 1989; James; Busia, 1994). No contexto do feminismo como um movimento político global para os direitos e a emancipação das mulheres, os padrões de conhecimento e a política feminista que as mulheres afro-americanas encontram nos Estados Unidos representam apenas um pequeno segmento refratado através das políticas raciais dicotômicas da supremacia branca nos Estados Unidos. Porque a mídia nos Estados Unidos retrata o feminismo como um movimento somente para brancas e porque muitas mulheres brancas têm aceitado esse ponto de vista do apartheid americano que leva a instituições segregadas de todos os tipos, 
incluindo organizações feministas, o feminismo é muitas vezes visto por ambos, negros e brancos como a propriedade cultural de mulheres brancas (Caraway, 1991).

Apesar do apagamento na mídia, muitas mulheres afroamericanas têm lutado muito contra esse feminismo excludente $e$ têm participado de atividades feministas que parecem ser somente para brancas. Em alguns casos, algumas mulheres negras têm desafiado diretamente o racismo dentro das organizações feministas controladas por mulheres brancas. A frase frequentemente citada de Sojourner Truth "não sou eu uma mulher?" tipifica essa tradição de longa data (Joseph, 1990). Em outros momentos, mesmo que a participação das mulheres negras nas organizações feministas permaneça em grande parte invisível por exemplo, a falta de reconhecimento de Pauli Murray como membro fundadora da $\mathrm{NOW}^{8}$-, as mulheres negras participaram de organizações feministas em posições de liderança. Em outros casos, as mulheres negras combinam agendas políticas supostamente divergentes. Por exemplo, Pearl Cleage observa que a política feminista negra e a política nacionalista negra não precisam ser contraditórias. Ela observa:

Eu não acho que você pode ser um verdadeiro nacionalista negro, dedicado à liberdade do povo negro sem ser feminista, pois, pessoas negras são compostas, afinal, tanto de mulheres quanto homens, e o feminismo não é nada mais ou nada menos do que uma crença na igualdade política, social e jurídica das mulheres (Cleage, 1994:180).

Usar o termo "feminismo negro" desestabiliza o racismo inerente ao apresentar o feminismo como uma ideologia e um movimento político somente para brancos. Inserindo o adjetivo "negro" desafia a brancura presumida do feminismo e interrompe o falso universal desse termo para mulheres brancas $e$ negras. Uma vez que muitas mulheres brancas pensam que as mulheres

8 National Organization for Women, criada em 1966, é uma das maiores organizações feministas dos Estados Unidos. 
negras não têm consciência feminista, o termo "feminista negra" destaca as contradições subjacentes à brancura presumida do feminismo e serve para lembrar às mulheres brancas que elas não são nem as únicas nem a norma "feministas". O termo "feminismo negro" também faz com que muitas mulheres afro-americanas se sintam desconfortáveis porque desafia as mulheres negras a confrontar os seus próprios pontos de vista sobre o sexismo e a opressão das mulheres. Porque a maioria das mulheres afroamericanas encontra suas próprias experiências reembaladas nos currículos escolares racistas e nos meios de comunicação, ainda que possam apoiar as ideias nas quais o feminismo descansa, um grande número de mulheres afro-americanas rejeita o termo "feminismo", pois elas percebem sua associação com a brancura. Muitas veem o feminismo como operando exclusivamente dentro dos termos "branca e americana" e percebem o seu oposto como sendo "negra e americana". Quando dadas essas duas falsas e estreitas escolhas, as mulheres negras rotineiramente escolhem a "raça" e deixam a questão menor de "gênero" de lado. Nessa situação, as mulheres negras que se identificam com o feminismo têm de ser recodificadas como sendo ou não negras ou menos autenticamente negras. O termo "feminista negra" também prejudica a confiança de longa data e em grande parte inquestionável na solidariedade racial negra que é uma raiz importante das filosofias políticas negras, especialmente abordagens do nacionalismo negro e do pluralismo cultural (Dyson, 1993). Usando a retórica da família que vê a família negra, a comunidade negra, a raça e a nação como uma série de caixas aninhadas, cada uma ganhando o significado com relação às outras, certas regras se aplicam a todos os níveis da organização "familiar". Assim como as famílias têm naturalizado hierarquias internas que dão, por exemplo, aos irmãos mais velhos autoridade sobre os mais jovens ou homens sobre as mulheres, os grupos que se definem como famílias-raciais invocam regras semelhantes (Collins, no prelo). Dentro das comunidades afro-americanas, uma regra é que as mulheres negras apoiarão os homens negros, em qualquer circunstância, uma regra não escrita que foi manipulada 
com bastante sucesso durante as audiências de confirmação de Clarence Thomas. Mesmo que Anita Hill fosse assediada por Clarence Thomas ${ }^{9}$, muitos proclamavam em barbearias e salóes de beleza que ela deveria ter mantido a boca fechada e não "aired dirty laundry". ${ }^{10}$ Mesmo que Thomas reformule a sua vida e de sua própria irmã por meio da estrutura de uma "welfare queen"11, em deferência à normativa de solidariedade racial, as mulheres negras deveriam ter mantido coletivamente a boca fechada. Aconselhando as mulheres negras a não permanecer em silêncio em face a esses abusos, o feminismo negro entra em conflito com códigos de silêncio como esses.

Várias dificuldades acompanham o uso do termo "feminismo negro". Um deles envolve o problema de equilibrar as preocupações genuínas de mulheres negras contra as pressões contínuas para absorver e reformular tais interesses no âmbito das estruturas feministas brancas. Por exemplo, a garantia dos direitos políticos e de desenvolvimento económico por meio de uma ação coletiva para mudar as instituições sociais continua a ser um ponto forte no feminismo de mulheres afro-americanas e mulheres de cor. No entanto, a ênfase em temas como a identidade pessoal, a compreensão da "diferença", desconstrução de múltiplos eu's das mulheres, e o modelo simplista da política expresso no slogan "o pessoal é político", que atualmente permeiam o feminismo das mulheres brancas norte-americanas na academia, pode trabalhar para minar o feminismo negro de sua perspectiva crítica. Os esforços das pensadoras negras contemporâneas para explicar uma tradição intelectual das mulheres negras de longa data com o rótulo "feminismo negro" pode atrair a atenção das mulheres

9 Em 1991. Anita Hill, testemunhou contra Clarence Thomas, então nomeado ao Supremo Tribunal de Justiça, por assédio sexual, durante o período em que ele foi seu supervisor na Comissão de Oportunidades Iguais de Trabalho nos Estados Unidos (EEOC).

${ }^{10}$ Em português a tradução seria "roupa suja se lava em casa".

11 "Welfare queen" é uma representação racista de uma mulher negra que vive se aproveitando dos sistemas de assistência social, termo popularizado por Ronald Reagan na sua campanha à presidência em 1976. 
brancas armadas com uma agenda feminista diferente. As questões levantadas por mulheres negras que não são vistas como explicitamente "feministas", principalmente as questões que afetam apenas mulheres, recebem muito menos sanção. Em certo sentido, a batida constante de ter que apoiar as mulheres brancas em seus esforços para promover um feminismo antirracista que permite que as mulheres negras acessem a rede mundial de ativismo das mulheres, desvia a energia das mulheres negras de questões sociais enfrentadas pelas comunidades afro-americanas. Porque o feminismo negro parece ser tão bem recebido pelas mulheres brancas no contexto da política racial dicotômica dos Estados Unidos, algumas mulheres negras legitimamente suspeitam de suas motivações.

Outro desafio para o feminismo negro diz respeito ao conflito direto com certos elementos de tradições religiosas negras. Por exemplo, a visibilidade de lésbicas brancas dentro do feminismo norte-americano em geral entra em conflito direto com artigos de fé de muitas mulheres negras, que consideram a homossexualidade como um pecado. Enquanto as mulheres afroamericanas individualmente podem aceitar gays, lésbicas $e$ bissexuais, especialmente se tais indivíduos são afro-americanas, as mulheres negras como uma coletividade têm, simultaneamente, se distanciado de movimentos sociais percebidos como requerendo a aceitação da homossexualidade. Como uma jovem negra perguntou: "por que eu tenho que aceitar o lesbianismo a fim de apoiar o feminismo negro?" A associação do feminismo com o lesbianismo continua a ser uma problemática para as mulheres negras. Reduzir as mulheres lésbicas negras à sua sexualidade, que escolhe as mulheres sobre os homens, reconfigura as lésbicas negras como inimigas dos homens negros. Essa redução não só constitui uma grave e má interpretação do lesbianismo negro - lésbicas negras têm pais, irmãos e filhos próprios e são incorporadas a uma série de relações tão complexas como as de seus irmãos e irmãs heterossexuais -, também simultaneamente, desvia a atenção de assuntos mais importantes (Lorde, 1984). Em última análise, quem é beneficiado 
quando a presença de mulheres negras em qualquer movimento social negro resulta em sua rejeição por afro-americanos?

O tema do lesbianismo e sua associação com o feminismo nas mentes de muitos afro-americanos também se sobrepõe a outra preocupação de muitas mulheres afro-americanas, ou seja, o seu compromisso com os homens afro-americanos. Outro desafio confrontado pelo feminismo negro diz respeito ao fato de ser percebido como separatismo - muitos afro-americanos definem o feminismo negro como sendo exclusivamente para mulheres negras e rejeitando os homens negros. Ao explicar sua preferência pelo "mulherismo", Sherley Ann Williams (1990:70) observa,

\begin{abstract}
um dos aspectos mais perturbadores da corrente negra crítica feminista (é) o seu separatismo - sua tendência a ver não só uma cultura de mulheres negras distinta, mas para ver a cultura como uma forma cultural separada que tem mais em comum com a experiência de mulheres brancas do que com a facticidade da vida afro-americana.
\end{abstract}

Essa é uma crítica válida do feminismo negro que, na minha opinião, deve ser resolvida se as principais ideias do feminismo negro esperam evitar o perigo de se tornar cada vez mais separadas das experiências e interesses das mulheres afroamericanas. Mas também fala de uma questão mais ampla, da contínua dificuldade de posicionar o feminismo negro entre o nacionalismo negro e o feminismo branco norte-americano. Efetivamente, o feminismo negro é obrigado a lidar com uma agenda feminista branca incapaz de ver o seu próprio racismo e também uma agenda nacionalista negra resistente a enfrentar seu próprio sexismo (Branco, 1990). Encontrar um lugar que acomoda essas agendas aparentemente contraditórias permanece indefinido (Christian, 1989).

\title{
Além do nome
}

Os esforços das mulheres afro-americanas para distinguir entre mulherismo e feminismo negro ilustram como a colocação 
das mulheres negras nas relações hierárquicas de poder promove lealdades diferentes, mas relacionadas a um ponto de vista autodefinido de mulheres negras. Enquanto as diferenças superficiais que distinguem mulheres afro-americanas que adotam mulherismo e feminismo negro parecem ser mínimas, os variados posicionamentos de mulheres negras em bairros, escolas, $e$ mercados de trabalho geram comparativamente diversos pontos de vista sobre as estratégias que as mulheres negras sentem acabarão por levar à autodeterminação das mulheres negras. Em certo sentido, enquanto que a filiação do mulherismo com o nacionalismo negro se relaciona com uma filosofia histórica e um conjunto de instituições sociais organizados em torno da centralidade da solidariedade racial para a sobrevivência negra, essa posição pode trabalhar para isolar o mulherismo de assuntos globais das mulheres. Ao mesmo tempo, enquanto o feminismo negro está ligado às lutas das mulheres, existentes tanto em nível nacional como global, promovendo uma agenda política clara em relação ao sexismo, sua filiação putativa com a brancura promove sua rejeição pela própria população que pretende servir.

Nenhum termo atualmente existente representa adequadamente a substância do que os diversos grupos de mulheres negras chamam de "mulherismo" ou de "feminismo negro". Talvez seja o momento de ir além de nomenclatura, aplicando as ideias principais advindas de mulheristas e feministas negras para a questão mais abrangente de analisar a centralidade de gênero na formação de uma gama de relações dentro das comunidades afro-americanas. Esta avaliação poderia abranger várias dimensões.

Em primeiro lugar, é importante ter em mente que o debate mulherismo/feminismo negro ocorre principalmente entre as mulheres negras relativamente privilegiadas. Mulherismo $e$ feminismo negro se beneficiariam por examinar o crescente descompasso entre o que as mulheres negras privilegiadas, especialmente aquelas na academia, identificam como temas importantes e o que o grande número de mulheres afroamericanas que estão fora do ensino superior considerariam digno 
de atenção. Embora essas mulheres afro-americanas se pareçam fisicamente umas com as outras e possam até ocupar o mesmo espaço, seus mundos permanecem decididamente diferentes. Podemos nos perguntar até que ponto o conteúdo temático de vozes emergentes de mulheres negras na academia fala para/com a massa de mulheres afro-americanas cuja alfabetização ainda lhes é negada. Acadêmicas negras exploram questões intrigantes de centros e margens e trabalham para desconstruir a identidade feminina negra; enquanto um grande número de mulheres negras permanece presa aos bairros organizados em torno de centros antigos do apartheid racial. A discussão de centros e margens, até mesmo o processo de vir a manifestar-se, que não aborda simultaneamente as questões de poder, deixa massas de mulheres negras fazendo a limpeza a seco, cozinhando o fast food, e espanando o computador da irmã que acaba de escrever o mais novo tratado teórico sobre as mulheres negras.

Em segundo lugar, mudando a ênfase da opressão sobre as mulheres negras à forma como o racismo institucionalizado opera de maneira mediada pelo gênero deve fornecer uma perspectiva mais clara de como a opressão de gênero trabalha em conjunto com a opressão racial para mulheres e homens negros. Essa mudança, potencialmente, abre novas opções políticas para os afro-americanos como um grupo. Assim como o feminismo não reside automaticamente em corpos femininos, o sexismo não reside em corpos masculinos. Pode ser o momento para separar filosofias políticas como o nacionalismo negro, afrocentrismo $e$ feminismo das categorias socialmente construídas de indivíduos criadas por relações históricas de racismo e sexismo. Os homens negros não podem ter as experiências de mulheres negras, mas eles podem apoiar as mulheres afro-americanas, defendendo filosofias antirracistas e antissexistas em seu trabalho intelectual $e$ político (ver, por exemplo, Marable, 1983; hooks; West, 1991; Awkward, 1995). Concentrando-se em gênero como uma estrutura de poder que trabalha com a raça, ofereceria espaços muito necessários para diálogos entre mulheres negras, homens negros e entre mulheres e homens negros. 
Essa abordagem promete beneficiar a comunidade negra como uma coletividade, porque modela sensibilidade à heterogeneidade, não só relativa aos gêneros, mas à classe, nacionalidade, sexualidade e idade, atualmente operando dentro do termo "comunidade negra". Assim, o debate do mulherismo/feminismo negro também proporciona uma excelente oportunidade para modelar um processo de construção de uma comunidade a partir da heterogeneidade e não da mesmice. Para as mulheres afro-americanas, dando vida aos significados aparentemente contraditórios que Alice Walker dá ao "mulherismo" e "feminismo negro" significa envolver-se na difícil tarefa de trabalhar com as diversas maneiras em que as mulheres negras têm sido afetadas pelos sistemas interlaçados de opressão. Algumas mulheres negras terão de lidar com as formas em que a opressão internalizada as tem afetado porque elas são pobres, enquanto outras devem lidar como o privilégio internalizado que acompanha o status das classes média e alta. Outras mulheres negras têm que lidar com os privilégios internalizados que recebem por se envolverem em comportamentos heterossexuais ou em como a cidadania americana proporciona-lhes direitos negados às mulheres em outras partes da diáspora. Pensar sobre a natureza interconectada dos vários sistemas de opressão e sobre as formas potenciais que tal interseccionalidade pode promover a resistência ajuda a movimentar as mulheres negras em direção ao mulherismo visionário de Walker. Um compromisso com a justiça social e a democracia participativa fornece algumas regras básicas fundamentais para as mulheres e homens negros a respeito de como se relacionar com as diferenças.

Finalmente, apesar da promessa dessa abordagem, é importante considerar as limitações do mulherismo, do feminismo negro, $e$ de todas as outras filosofias progressistas. Identificando-se com "mulherismo", "feminismo negro", ou qualquer outra coisa, não é possível que as mulheres negras tenham uma visão superior do que a comunidade deveria ser, quanta justiça poderia sentir, $e$ assim por diante. Isso pressupõe que tal perspectiva chega sem conflito, rigor intelectual e luta política. Enquanto a localização 
particular das mulheres negras proporciona um ângulo diferente de visão sobre a opressão, essa perspectiva não é privilegiada $e$ nem completa. Nesse sentido, abraçar as ideias de heterogeneidade dentro das comunidades de mulheres negras martelando um ponto de vista das mulheres negras autodefinidas abre o caminho para outros grupos que desejam seguir. Como mulheres negras podemos liderar o caminho ou podemos seguir atrás. As coisas vão continuar a seguir em frente, independentemente da nossa escolha.

\section{Referências bibliográficas}

AWKWARD, Michael. Negotiating Difference: Race, Gender, and the Politics of Positionality. Chicago, University of Chicago Press, 1995.

CAnNon, Katie G. Black Womanist Ethics. Atlanta, Scholars Press, 1988.

CARAWAY, Nancie. Segregated Sisterhood: Radsm and the Politics of American Feminism. Knoxville, University of Tennessee Press, 1991.

CARBY, Hazel. The Multicultural Wars. In: Wallace; Michele; Dent, Gina (ed.) Black Popular Culture. Seattle, Bay Press, 1992, pp.187-99.

Christian, Barbara. "But Who Do You Really Belong To - Black Studies or Women's Studies?”. Women's Studies 17, 1-2, 1989, pp.17-23.

Cleage, Pearl. Deals with the Devil and Other Reasons to Riot. New York, Ballantine Books, 1993.

COLLINS, Patricia Hill. Black Feminist Thought: Knowledge, Consciousness, and the Politics of Empowerment. New York, Routledge, Chapman and Hall, 1990.

. Forthcoming. Interseccion of Race, Class, Gender, and Nation: Some Implications for Black Family Studies. Journal of Comparative Family Studies.

DAVIS, Angela. 1989. Women, Culture, and Politics. New York: Random House.

DUBEY, Madhu. Black Women Novelists and the Nationalist Aesthetic. Bloomington, Indiana University Press, 1994. 
DuCille, Ann. The Occult of True Black Womanhood: Critical Demeanor and Black Feminist Studies. Signs 19(3), 1994, pp.591629.

DYSON, Michael. Reflecting Black: African-American Cultural Criticism. Minneapolis, University of Minnesota Press, 1993.

HOOKS, bell. Talking Back: Thinking Feminist, Thinking Black. Boston, South End Press, 1989.

; WEST, Cornel. Breaking bread: Insurgent Black Intellectual Life. Boston, South End Press, 1991.

JAMES, Stanlie; BusIA, Abena (eds.). Theorizing Black Feminisms. New York, Routledge, 1994.

JORDAN, June. Technical Difficulties: African-American Notes on the State of the Union. New York, Pantheon Books, 1992.

JOSEPH, Gloria I. Sojourner Truth: Archetypal Black Feminist. In: BRAXTON, Joanne; McLaughlin, Andrée Nicola (ed.). Wild Women in the Whirlwind. New Brunswick, Rutgers University Press, 1990, pp.35-47.

LORDE, Audre. Sister Outsider. Trumansburg, NY, The Crossing Press, 1984.

MARABLE, Manning. Grounding with My Sisters: Patriarchy and the Exploitation of Black Women. In: How Capitalism Underdeveloped Black America. Boston, South End Press, 1983, pp.69-104.

MASSEY, Douglas S.; DENTÓN, Nancy A. American Apartheid: Segregation and the Making of the Underclass. Cambridge, Harvard University Press, 1993.

Omolade, Barbara. The Rising Song of African American Women. New York, Routledge, 1994.

PINKNEY, Alphonso. Red, Black, and Green: Black Nationalism in the United States. London, Cambridge University Press, 1976.

SMITH, Barbara. The Truth That Never Hurts: Black Lesbians in Fiction in the 1980s. In: BRAXTON, Joanne; MCLAUGHLIN, Andrée Nicola (ed.). Wild Women in the Whirlwind. New Brunswick, Rutgers University Press, 1990, pp.213-245. 
SquiRES, Gregory D. Capital and Communities in Black and White: The Intersections of Race, Class, and Uneven Development. Albany, SUNY Press, 1994.

VAN DeBurg, William L. New Day in Babylon: The Black Power Movement and American Culture, 1965-1975. Chicago, University of Chicago Press, 1992.

WALKER, Alice. In Search of Our Mothers' Gardens. New York, Harcourt, Brace Jovanovich, 1983.

WhITE, E. Frances. Africa on My Mind: Gender, Counter Discourse and African-American Nationalism. Journal of Women's History 2, 1 Spring, 1990, pp.73-97.

WiLliAmS, Sherley Ann. Some Implications of Womanist Theory. In: GATES, Henry Louis (ed.). Reading Black, Reading Feminist: A Critical Anthology. New York, Meridian, 1990, pp.68-75. 